\title{
Análise do consumo de água e produtos químicos em indústrias têxteis no Agreste Pernambucano
}

O consumo de água e produtos químicos nas indústrias/lavanderias têxteis é elevado, necessitando desta forma de alternativas visando mitigar os impactos ao meio ambiente. Assim, objetivou-se este estudo analisar as o consumo de água e produtos químicos poluentes utilizados pelas indústrias de beneficiamento de jeans no agreste Pernambucano. O trabalho foi desenvolvido em três cidades do Agreste Pernambucano, conhecidas como polo têxtil. Foram aplicados questionários em 18 indústrias/lavanderias têxteis a fim de conhecer o consumo de água bruta, percentual de efluentes tratados, volume de água depositado nos rios e a quantidade de produtos químicos utilizado em cada etapa de beneficiamento de jeans. O consumo de água bruto, de produto químico, o reuso e a produção de jeans eleva-se, à medida que as empresas crescem com relação ao porte. O produto comercial denominado Amaciante, princípio ativo peroxido de hidrogênio é o mais utilizado pelas indústrias/lavanderias têxteis no agreste pernambucano. Quanto maior o porte da indústria/lavanderia têxtil mais elevado o consumo de água, produtos químicos e efluentes lançados nos rios. O permanganato de potássio é um dos produtos químicos utilizados no beneficiamento de jeans, mais poluentes e persistentes em meios aquáticos. As indústrias/lavanderias têxteis são grandes agentes poluidoras, uma vez que usam elevados volumes de água e produtos químicos, necessitando de normas mais rígidas quanto a emissão e despejos de seus resíduos. Faz-se necessário a busca por alternativas visando reduzir o consumo de água bruta, como reuso, manutenção continua de maquinas e substituição de produtos químicos poluentes por técnicas sustentáveis.

Palavras-chave: Beneficiamento de jeans; Permanganato de potássio; Escassez de água; Sustentabilidade; Proteção ambiental.

\section{Analysis of water and chemical consumption in textile industries in Agreste Pernambucano}

\begin{abstract}
The consumption of water and chemical products in textile industries/laundries is high, thus requiring alternatives to mitigate impacts on the environment. Thus, this study aimed to analyze the consumption of polluting water and chemical products used by the jeans processing industries in the Agreste Pernambuco state. The work was developed in three cities in Agreste Pernambucano, known as the textile hub. Questionnaires were applied in 18 textile industries/laundries in order to find out the consumption of raw water, the percentage of treated effluents, the volume of water deposited in the rivers and the amount of chemicals used in each step of jeans processing. The consumption of raw water, chemical products, reuse and the production of jeans increases, as companies grow in relation to size. The commercial product called Softener, hydrogen peroxide active ingredient is the most used by textile industries/laundries in the harsh Pernambuco. The larger the size of the textile industry/laundry, the higher the consumption of water, chemicals and effluents discharged into rivers. Potassium permanganate is one of the chemicals used in the processing of jeans, more polluting and persistent in aquatic environments. Textile industries/laundries are major polluting agents, since they use high volumes of water and chemicals, requiring stricter standards regarding the emission and dumping of their waste. The search for alternatives is necessary to reduce the consumption of raw water, such as reuse, continuous maintenance of machines and replacement of polluting chemicals with sustainable techniques.
\end{abstract}

Keywords: Jeans processing; Potassium permanganate; Water shortage; Sustainability; Environmental Protection.

Topic: Desenvolvimento, Sustentabilidade e Meio Ambiente

Reviewed anonymously in the process of blind peer.
Received: 01/01/2021

Approved: 28/01/2021
Clarissa Maria Ramalho de Sá Rocha (iD)

Universidade Federal de Campina Grande, Brasil

http://lattes.cnpq.br/3548596786557495

http://orcid.org/0000-0002-7428-1752

clarissa r2@yahoo.com.br

Vicente de Paulo Rodrigues da Silva (iD)

Universidade Federal de Campina Grande, Brasil

http://lattes.cnpq.br/3750344965379269

http://orcid.org/0000-0003-4914-4833

vicente.paulo@ufcg.edu.br

Patricia Ferreira da Silva (1)

Universidade Federal de Campina Grande, Brasil

http://lattes.cnpq.br/8146309314429987

http://orcid.org/0000-0002-4580-2336

patrycyafs@yahoo.com.br

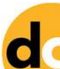

DOI: 10.6008/CBPC2179-6858.2021.001.0047
João Hugo Baracuy da Cunha Campos (iD) Universidade Estadual da Paraíba, Brasil http://lattes.cnpq.br/2677113447182816 http://orcid.org/0000-0002-4796-0696 joaohugo@uepb.edu.br
Referencing this:

ROCHA, C. M. R. S.; SILVA, V. P. R.; SILVA, P. F.; CAMPOS, J. H. B. C.. Análise do consumo de água e produtos químicos em indústrias têxteis no Agreste Pernambucano. Revista Ibero Americana de Ciências Ambientais, v.12, n.1, p.581-594, 2021. DOI: 


\section{INTRODUÇÃO}

As indústrias/lavanderias do jeans se utilizam de processos físicos e químicos aos quais as peças são submetidas, visando melhorar suas características, uma vez que o mercado mundial requer cada vez mais peças elaboradas, com detalhes que requerem processos como: alvejamento, tingimento, amaciamento, secagem, centrifugação, desengomagem e descoloração (ARAÚJO et al., 2019; JERÔNIMO et al., 2012).

De acordo com Silva et al. (2020) esses processos de beneficiamento utilizados pelas indústrias/lavanderias de jeans, em decorrência de técnicas ultrapassadas necessitam de grandes volumes de água bruta e de produtos químicos como: permanganato de potássio, peroxido de hidrogênio, metassilicato de sódio, metabissulfito de sódio, hipoclorito de sódio e corantes, no entanto, cabe destacar que o polo têxtil que envolve as cidades de Toritama, Caruaru e Santa Cruz do Capiberibe agreste Pernambucano é uma região que apresenta escassez hídrica, visto que evapora mais água do que chove, com índice pluviométrico anual de $550 \mathrm{~mm}$. Além disso, os rios Ipojuca e Capiberibe recebem um cerca de 16\% de poluentes dessas indústrias (SILVA et al., 2020; ALKAYA et al., 2014; ALMEIDA, 2013; COSTA et al., 2019).

O elevado consumo hídrico pelo setor é amplificado pela manutenção precária do maquinário (válvulas apresentando defeitos, vazamentos, água fluindo mesmo com a máquina parada), equipamento para lavagem em condição de ineficiência e ciclos excessivamente longos, dificultando o reuso de água. Apesar de algumas empresas estarem adotando técnicas que visem o reuso sustentável da água. A inovação empregada na recirculação da água, inclusive, reduz o emprego desnecessário de energia e de volume de efluente a ser tratado (ARAÚJO et al., 2019).

Alkaya et al. (2014) afirmam ainda que as indústrias/As lavandarias de jeans estão entre as atividades industriais mais impactantes na área ambiental de devido ao seu elevado potencial poluidor e complexidade química dos efluentes gerados, em decorrência da gama de produtos químicos utilizados nas etapas de beneficiamento de jeans. Diante deste cenário, a adoção de técnicas que visem a proteção, em especial, dos recursos hídricos é essencial nessa atividade, uma vez que a indústria de beneficiamento têxtil tem como principal insumo a água.

Nesse sentido, estas empresas precisam se adequar à nova realidade de preservação dos corpos hídricos, assim, a fim de combater os problemas de disponibilidade e conservação dos recursos naturais, está ocorrendo um processo de mudança de comportamento, e as empresas, seja por força de lei ou por conscientização, começam a adotar uma postura sustentável (DONAIRE, 2011). As principais medidas que visam mitigar os efeitos dessas indústrias sobre os corpos hídricos, está atrelada a técnicas que visem o reuso da água, substituição de produtos químicos mais poluentes por produtos que agridam menos o meio ambiente como: utilização da marcação no jeans por laser que substituir o jato de areia, o permanganato de potássio e o esmeril; outra técnica é o uso do ozônio, que reduz o uso da água e a utilização de produtos químicos (SINDILAV, 2017).

De acordo com Silva et al. (2020) a técnica de reuso de água e a substituição de produtos químicos poluentes nas indústrias/lavanderias têxtis são maneiras importantes para manutenção da competitividade, 
uma vez que os consumidores estão cada vez mais buscando por produtos com viés sustentável. Nesse contexto, para manter-se neste espaço competitivo e atender às necessidades e normas ambientais estabelecidas pelo poder público, as indústrias/lavanderias precisam inovar, inclusive, na sistemática de tratamento de água, a fim de reutilizá-la, além de buscar produtos menos poluentes para utilizar nas etapas de beneficiamento.

Diante do crescente problema da crise hídrica e ambiental, torna-se fundamental a utilização de estratégias, que buscam auxiliar no uso dos recursos naturais de forma sustentável. Para Silva et al. (2020) a sustentabilidade hídrica das indústrias/lavanderias de beneficiamento de jeans na região agreste de Pernambuco pode ser alcançada com medidas visando a correção de equipamento e a adoção do reuso de forma massiva e uso de produtos alternativos. Cabe destacar que além do consumo excessivo de água, as indústrias/lavanderias de jeans possuem um elevado consumo de produtos químicos altamente poluentes ao meio ambiente. Assim sendo, objetivou-se com este estudo analisar as o consumo de água e produtos químicos poluentes utilizados pelas indústrias de beneficiamento de jeans no agreste Pernambucano.

\section{MATERIAIS E MÉTODOS}

\section{Área de Estudo}

A pesquisa foi desenvolvida junto às indústrias/ lavanderias têxteis localizadas no Polo de Confecções do Agreste de Pernambuco, especificamente nas cidades de Toritama (Latitude: 7o, 59’ 56” Sul, Longitude: 36ㅇ 3’ 8" Oeste), Caruaru (Latitude: 08ㅇ 17' 00" Sul, Longitude: 35은 58' 34" Oeste) e Santa Cruz do Capibaribe (Latitude: $7^{\circ} 57^{\prime} 26^{\prime \prime}$ Sul, Longitude: 36¹2'16" Oeste) (Figura 1).

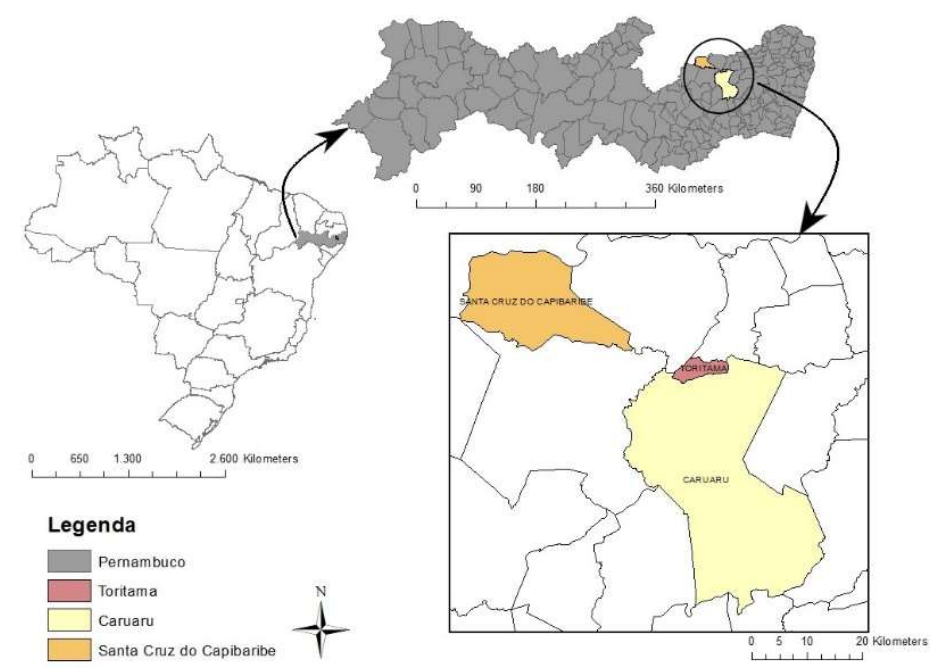

Figura 1: Mapa do Brasil com destaque para as cidades do Polo de Confecções do Agreste pernambucano.

O clima da região, segundo a classificação Köppen, é do tipo semiárido Bwh, com temperatura média anual de 26 으. A evapotranspiração potencial da região varia de 1500 a 1900 mm anuais, com período seco predominante de 6 a 8 meses. A precipitação é irregular concentrada em 2 a 3 meses do ano e média anual em torno de 550 mm (BELTRÃO et al., 2005). Sendo que Toritama possui uma precipitação média anual de 516 mm, Caruaru 516 mm e Santa Cruz do Capibaribe de 417,49mm e a intensidade da precipitação 
considerada como moderada para as três cidades (Nobrega et al., 2015; Medeiros, 2019).

\section{Levantamento de dados}

Os dados foram levantados dentro de um universo de 17 indústrias/lavanderias, sendo 6 localizadas na cidade de Caruaru, agreste do estado de Pernambuco, 7 lavanderias localizadas na cidade de Toritama PE e 4 localizadas em Santa Cruz do Capibaribe - PE. Essa região corresponde a 15 \% do território Pernambucano (SEBRAE, 2017). As indústrias/lavanderias têxteis foram identificadas da seguinte forma: S. C. do Capibaribe - A; S. C. do Capibaribe - B; S. C. do Capibaribe - C; S. C. do Capibaribe - D; Toritama - A; Toritama - B; Toritama - C; Toritama - D; Toritama - E; Toritama - F; Toritama - G; Caruaru - A; Caruaru B; Caruaru - C; Caruaru - D; Caruaru-E e Caruaru - F.

A obtenção dos dados a respeito do consumo de água bruta, percentual de reuso e de efluentes depositados nos rios e dos principais produtos químicos utilizados no beneficiamento de jeans, foram quantificados por meio da aplicação de questionários aos responsáveis pelas indústrias/lavanderias estudadas no período de 2017 a 2018.

Nos questionários abordaram-se as seguintes informações: dados da empresa, como tempo de funcionamento das indústrias/ Lavanderia, quantidade de funcionários, CNPJ, número de peças produzidas, resíduos gerados durante o processo que utiliza os recursos hídricos e destinos dos mesmos; destinos dos efluentes industriais; utilização de medidas de conservação ao meio ambiente; origem da matéria prima, volume de efluente depositado no rio. As informações coletadas serviram de suporte para analisar os possíveis impactos ambientais no Pólo de Confecções de Santa Cruz do Capibaribe, Toritama e Caruaru.

\section{Quantidade de peças produzidas, consumo de água bruta, percentual de água reutilizada e volume de água depositado nos rios}

Em cada empresa visitada foi quantificado o número de peças produzidas (NPL mês), informações essas obtidas com as pessoas que recepcionou no momento da aplicação dos questionários. Cabe ainda destacar que a quantidade de peças produzidas assim como o consumo de água varia de acordo como o ano e a moda que poderá exigir maior ou menor quantidade e porte da indústria/lavanderia têxtil.

As indústrias/lavanderias foram classificadas quanto ao porte de acordo com o número de peças produzidas por dia, assim aquelas que produzem menos de 750 peças dias ${ }^{-1}$ foram consideradas de pequeno porte, as que produzem de 750 a 3000 peças dia ${ }^{-1}$ de médio porte e as de grande porte aquelas que produzem acima de 3000 peças dia $^{-1}$. Considerou-se que uma peça jeans tem, em média, $500 \mathrm{~g}$.

O consumo de água bruta ( $C A B)$ em $\left(\mathrm{m}^{3} \mathrm{mês}^{-1}\right)$ foi quantificada com base no volume de água utilizado para cada etapa de beneficiamento de jeans, dado este fornecido pelos empresários no momento da aplicação dos questionários.

O percentual de água reutilizada (\% água reutilizada), determinou-se com base nos dados obtidos por meio da aplicação os questionários assim como a percentagem de efluente depositado no rio (\% efluente) e o volume de efluente lançado no rio (VELR) em $\left(\mathrm{m}^{3} \mathrm{mês}^{-1}\right)$ para cada uma das empresas visitadas. 


\section{Principais poluentes utilizados}

Os principais poluentes analisados no estudo foram definidos de acordo com levantamento feito com base no questionário aplicado as indústrias/lavanderias têxteis, onde se obteve o consumo cloro (CC) princípio ativo (hipoclorito de sódio), de permanganato de potássio (CPP), de metabissulfito de sódio (CMS), de amaciante (CA) princípio ativo (peroxido de hidrogênio) e de metassilicato (CM) em (kg mês ${ }^{-1}$ ) para as de acordo com o porte.

Os produtos químicos foram selecionados de acordo com as principais etapas das lavanderias, as etapas identificadas foram: Descoloração/Used (permanganato de potássio), Alvejamento (metassilicato de sódio), Neutralização (metabissulfito de sódio), Amaciamento (peroxido de hidrogênio) e Tingimento (hipoclorito de sódio).

Os principais produtos químicos utilizados nas diferentes fases de beneficiamento do jeans na região do agreste de Pernambuco, juntamente com o peso molecular, etapas de beneficiamento e finalidade de cada etapa, encontram-se na Tabela 1.

Tabela 1: Principais produtos químicos empregados nas diversas etapas de beneficiamento do jeans.

\begin{tabular}{|c|c|c|c|c|}
\hline $\begin{array}{ll}\text { Etapas } & \text { do } \\
\text { Beneficiamento } & \text { de } \\
\text { Jeans } & \\
\end{array}$ & $\begin{array}{l}\text { Respectivas } \\
\text { finalidades }\end{array}$ & Produto Químico & Formula Molecular & $\begin{array}{l}\text { Peso Molecular (gmol- } \\
\text { 1) }\end{array}$ \\
\hline $\begin{array}{l}\text { Descoloração do jeans/ } \\
\text { Used }\end{array}$ & Remover coloração & $\begin{array}{l}\text { Permanganato de } \\
\text { potássio }\end{array}$ & $\mathrm{KMnO}_{4}$ & 158,00 \\
\hline Alvejamento & $\begin{array}{l}\text { Remover coloração } \\
\text { amarela (natural) do } \\
\text { material têxtil }\end{array}$ & Metassilicato de sódio & $\mathrm{Na}_{2} \mathrm{SiO}_{3}$ & 122,06 \\
\hline Neutralização & $\begin{array}{l}\text { Remover o excesso de } \\
\text { permanganato e } \\
\text { proporciona um efeito } \\
\text { de manchas brancas } \\
\text { aleatórias na superfície } \\
\text { do tecido. } \\
\text { Remover coloração }\end{array}$ & Metabissulfito de sódio & $\mathrm{Na}_{2} \mathrm{~S}_{2} \mathrm{O}_{5}$ & 190,10 \\
\hline Amaciamento & $\begin{array}{l}\text { amarela (natural) do } \\
\text { material têxtil }\end{array}$ & Peroxido de hidrogênio & $\mathrm{H}_{2} \mathrm{O}_{2}$ & 34,01 \\
\hline Tingimento & $\begin{array}{l}\text { Conferir coloração ao } \\
\text { material têxtil }\end{array}$ & Hipoclorito de sódio & $\mathrm{NaClO}$ & 74,44 \\
\hline
\end{tabular}

Fonte: Adaptado do SINDITEXTIL (2017).

\section{RESULTADOS E DISCUSSÃO}

\section{Quantificação do consumo de água bruta, número de peças produzidas e percentual de água reutilizada nas lavanderias}

As indústrias/lavandarias têxteis em estudo apresentaram dados distintos quanto consumo de água bruta (CAB) em $\left(\mathrm{m}^{3} \mathrm{mês}^{-1}\right.$ ), número de peças lavadas (NPL, mês), percentual de água reutilizada (\% água reutilizada), percentagem de efluente depositado no rio (\% efluente) e volume de efluente lançado no rio (VELR) em $\left(\mathrm{m}^{3} \mathrm{mês}^{-1}\right)$. As indústrias/lavandarias têxteis foram classificadas quanto ao porte de acordo com o número de peças lavadas por mês em pequeno, médio e grande porte. Nota-se que das 17 indústrias/lavandarias têxteis visitadas 9 foram classificadas como de pequeno porte, cinco de médio porte e três como de grande porte distribuídas nas cidades estuadas (Tabela 2). 
Tabela 2: Classificação das lavanderias quanto ao porte e valores observados para o consumo de água bruta (CAB) em $\left(\mathrm{m}^{3} \mathrm{mês}^{-1}\right)$, número de peças lavadas (NPL, mês), percentual de água reutilizada (\% água reutilizada), percentagem de efluente depositado no rio (\%efluente) e volume de efluente lançado no rio (VELR) em $\left(\mathrm{m}^{3} \mathrm{mês}^{-1}\right)$.

\begin{tabular}{|c|c|c|c|c|c|c|}
\hline \multirow[b]{2}{*}{ Porte das Lavanderias } & \multirow[b]{2}{*}{ Lavanderias } & \multicolumn{5}{|c|}{ Valores observados } \\
\hline & & $\begin{array}{l}\text { CAB } \\
\left(m^{3} \mathrm{mês}^{-1}\right)\end{array}$ & NPL (mês) & $\%$ água reutilizada & $\begin{array}{l}\% \\
\text { efluente }\end{array}$ & $\begin{array}{l}\text { VELR } \\
\left(\mathrm{m}^{3} \mathrm{mês}^{-1}\right)\end{array}$ \\
\hline & S. C. do Capibaribe - A & 216,00 & 5520,00 & 40,00 & 60,00 & 129,00 \\
\hline & S. C. do Capibaribe - B & 336,00 & 6360,00 & 00,00 & 100,00 & 336,00 \\
\hline & S. C. do Capibaribe - C & 144,00 & 6000,00 & 40,00 & 60,00 & 86,40 \\
\hline & Toritama - A & 288,00 & 9600,00 & 40,00 & 60,00 & 172,60 \\
\hline \multirow[t]{7}{*}{ Pequeno } & Toritama - B & 240,00 & 6720,00 & 00,00 & 100,00 & 240,00 \\
\hline & Toritama - C & 260,00 & 7800,00 & 40,00 & 60,00 & 216,00 \\
\hline & Toritama - D & 192,00 & 7200,00 & 00,00 & 100,00 & 192,00 \\
\hline & Caruaru - A & 408,00 & 7200,00 & 45,00 & 55,00 & 224,40 \\
\hline & Caruaru - B & 168,00 & 5280,00 & 40,00 & 60,00 & 100,80 \\
\hline & S. C. do Capibaribe - D & 840,00 & 31200,00 & 48,00 & 52,00 & 436,00 \\
\hline & Toritama - E & 792,00 & 21600,00 & 60,00 & 40,00 & 475,20 \\
\hline \multirow[t]{4}{*}{ Médio } & Caruaru - C & 1320,00 & 28800,00 & 70,00 & 30,00 & 396,00 \\
\hline & Caruaru - D & 672,00 & 52800,00 & 52,00 & 48,00 & 322,56 \\
\hline & Caruaru - E & 960,00 & 60000,00 & 63,00 & 37,00 & 355,20 \\
\hline & Toritama - F & 5880,00 & 76800,00 & 90,00 & 40,00 & 2352,00 \\
\hline \multirow[t]{2}{*}{ Grande } & Toritama - G & 7200,00 & 96000,00 & 85,00 & 15,00 & 1080,00 \\
\hline & Caruaru - F & 4800,00 & 72000,00 & 78,00 & 22,00 & 1056,00 \\
\hline \multicolumn{7}{|c|}{ Média de valores } \\
\hline Pequeno & - & 261,33 & 6853,33 & 27,22 & 72,78 & 188,67 \\
\hline Médio & - & 916,80 & 38880,00 & 46,60 & 35,40 & 317,95 \\
\hline Grande & - & 5960,00 & 81600,00 & 84,33 & 25,67 & 1496,00 \\
\hline
\end{tabular}

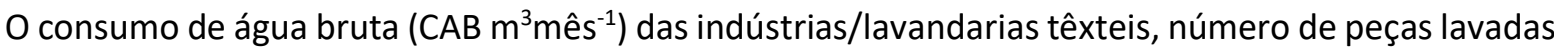
(NPL, mês), percentual de água reutilizada (\% água reutilizada), percentagem de efluente depositado no rio (\% efluente) e volume de efluente lançado no rio (VELR $\mathrm{m}^{3} \mathrm{mês}^{-1}$ ) variam muito de acordo com porte, assim como de acordo com a cidade a qual está inserida (Tabela 2). Nota-se que o consumo de água bruta, o número de peças produzidas, o percentual de água reutilizada e o volume de efluente lançado no rio é crescente, quando se compara lavanderias de pequeno, médio e grande porte (Tabela 2). Observa-se ainda, que as indústrias/lavandarias têxteis de pequeno porte da cidade de Santa Cruz do Capibaribe consomem em média $233 \mathrm{~m}^{3} \mathrm{mês}^{-1}$ e produzem em média 5900 peças mês $\mathrm{s}^{-1}$ (Tabela 2).

Já a indústria/lavanderia têxtil de Toritama consideradas de pequeno porte chegam a consumir de água bruta (CAB) $245 \mathrm{~m}^{3} \mathrm{mês}^{-1}$ e produzem em média 7830 peças mês ${ }^{-1}$. Para a cidade de Caruaru nota-se que as lavanderias têxtis de pequeno porte demandam em média $288 \mathrm{~m}^{3} \mathrm{mês}^{-1}$ para uma capacidade de produção de 6240 peças mês ${ }^{-1}$ (Tabela 2).

A indústria/lavanderia têxtil Toritama ' $A$ ' consome de água bruta $288 \mathrm{~m}^{3} \mathrm{mes}^{-1}$ e produzem cerca de 9600 peças mês ${ }^{-1}$ (Tabela 2). No entanto, cabe destacar que uma das indústrias/lavandarias têxteis classificadas como de pequeno porte Caruaru 'A' possui um CAB de $408 \mathrm{~m}^{3} \mathrm{mes}^{-1}$ e uma produção de 7200,00 peças mês ${ }^{-1}$. É importante salientar que mesmo consumindo mais água a indústrias/lavandarias têxteis de pequeno porte Caruaru ' $A$ ' tem uma produção de peças mensais inferior a Toritama ' $A$ ', fato que pode ser justificado pela maior eficiência produtiva das empresas da cidade de Toritama.

Monteiro et al. (2019) afirmam que a produção de jeans é o forte da cidade de Toritama-PE, mensalmente as indústrias/lavanderias têxteis instaladas no município respondem por 5.394.137,00 (cinco milhões, trezentos e noventa e quatro mil, cento e trinta e sete) peças, sendo que os principais itens 
fabricados são: calças $(36,2 \%)$, short $(35,25 \%)$, bermuda $(9,9 \%)$, calça feminina $(5,3 \%)$ e saia $(4,5 \%)$; que juntos representam 91\% (noventa e um por cento) da produção.

Esses valores de consumo de água bruta mensal observados no presente estudo para indústria/lavanderia têxtil de pequeno porte são semelhantes aos relatados por Viana et al. (2018) que obtiveram para empresas de pequeno porte em média um consumo de água bruta de $356 \mathrm{~m}^{3} \mathrm{mês}^{-1}$ para uma demanda mensal de aproximadamente 8250 peças de jeans beneficiadas.

Já Marcelino (2013) afirma que as indústrias/lavanderias têxtis de pequeno porte mensalmente, procedem a lavagem de, aproximadamente, 10.000 peças, um consumo de água bruta é de $20 \mathrm{~m}^{3} \mathrm{dia}^{-1}$, ou seja, cerca de $600 \mathrm{~m}^{3} \mathrm{mês}^{-1}$. Resultado este que se aproxima do observado no presente estudo, uma vez que as empresas de pequeno porte têm produção e consumo de água bruta similar.

Para as indústrias/lavanderias têxtil classificadas como de médio porte a cidade de Santa Cruz do Capibaribe apresenta uma demanda superior a 30000 mil peças mensais para um consumo de $840 \mathrm{~m}^{3} \mathrm{mês}^{-1}$, em contrapartida a cidade de Toritama possui um consumo de $792 \mathrm{~m}^{3} \mathrm{mês}^{-1}$ para uma demanda de 21600 mil peças mensais (Tabela 2). Já a cidade de Caruaru possui um consumo de água bruta superior a Santa Cruz do Capibaribe e Toritama, correspondendo a uma média de $984 \mathrm{~m}^{3}$ mês ${ }^{-1}$ para um número de peças médios mensais de 47200 (Tabela 2).

Dentre as empresas de médio porte o destaque é a Caruaru ' $C$ ' que possui um consumo de 672 $\mathrm{m}^{3} \mathrm{mês}^{-1}$, com uma produção de 52800 peças mês ${ }^{-1}$. Esse resultado é condizente com os obtidos para a cidade de Caruaru por Viana et al. (2018) para indústria/lavanderia têxtil de médio porte, visto que obtiveram para um consumo de $1260 \mathrm{~m}^{3}$ mês $^{-1}$ uma produção de peças mensais de 52500 .

A cidade de Santa Cruz do Capibaribe não possui indústria/lavanderia têxtil classificadas como de grande porte. Contudo, a cidade de Toritama consome em nas indústrias de grande porte cerca de 6540 $\mathrm{m}^{3} \mathrm{mês}^{-1}$ para um número de peças de 86400 . Já Caruaru consome $4800 \mathrm{~m}^{3} \mathrm{mês}^{-1}$ tendo uma produção 72000 peças mês ${ }^{-1}$ (Tabela 2).

Segundo o SEBRAE (2013), para lavar uma peça de jeans se gasta em torno de 60 a 100 litros de água, então, se pode imaginar a quantidade de litros utilizados em uma indústria/lavanderia têxtil que lava no mínimo 20.000 peças mês ${ }^{-1}$. Fato que pode ser observado nas indústrias/lavanderias têxtis de médio e grande porte, que possuem uma produção superior a 20000 peças mês ${ }^{-1}$.

As indústrias/lavanderias têxtis de pequeno porte reutilizam em média cerca de $27 \%$, de médio porte $46 \%$ e de grande porte $84 \%$ de água utilizada nos processos de beneficiamento do jeans. Assim, a percentagem de efluente depositado no rio (\% efluente) é maior nas indústrias/lavanderias têxtis de pequeno porte, quando comparada as de médio e grande porte, apesar das indústrias/lavanderias têxtis de pequeno porte lançar um volume de efluente no rio inferior as de médio e grande porte (Tabela 2). Essa característica está associada ao consumo de água bruta, visto que por mais que as lavanderias de médio e grande porte tenham um percentual de reuso maior elas consomem mais água que as de pequeno porte, assim o VELR $\left(\mathrm{m}^{3} \mathrm{mês}^{-1}\right)$ ainda será elevado (Tabela 2).

Para Silva et al. (2012) em muitos casos existe a falta de interesse em aplicar algum tipo de 
tratamento da água, ou de melhorar a eficiência do processo de beneficiamento de jeans, fato que pode estar relacionada ao posicionamento dos demandantes dos serviços prestados pelas indústrias/lavanderias têxtil. Possivelmente, a obtenção de um sistema mais moderno de tratamento da água visando o reuso, elevaria os custos de produção das indústrias/lavanderias, o que seria refletido no seu preço final, diminuindo a demanda pelos serviços.

Pinilla et al. (2017) pontuam que ainda que introdução de sistemas modernos de tratamento de efluentes têxteis consistem em processos de separação por membranas, estes viabilizam um padrão de qualidade muito diferenciado em relação aos métodos tradicionais, principalmente em relação à desinfecção, em função da redução do consumo de produtos químicos. Essas técnicas de tratamento contribuem para a redução do consumo de recursos naturais, produtos químicos, energia elétrica e dispêndio financeiro em relação à cobrança pelo uso da água (SINDITÊXTIL, 2017).

As indústrias/lavanderias têxtis são consideradas empresas com elevado consumo de água em suas etapas de beneficiamento. De acordo com Viana et al. (2018) esse consumo elevado de água pode vir a causar alguns impactos como a escassez de água, a poluição dos rios entre outros. Contudo, Lorena et al. (2016) afirmam que o reuso da água dentro do processo industrial das lavanderias têxteis é considerada uma alternativa importante para redução dos poluentes gerados nas indústrias.

Barros (2012) relatam que o uso de tecnologias disponíveis para reduzir a contaminação e o consumo hídrico não pode ser descartada dentro das empresas. Deste modo, o estabelecimento de estratégias sustentáveis para a redução do consumo e aumento do reuso se tornam necessários, além de planejamento e operações corretas de reuso, que podem contribuir para a diminuição da poluição ambiental.

Para tentar controlar esses níveis de efluente depositado nos rios o SINDILAV (2017) criou uma cartilha de boas práticas ambientais para indústrias/lavanderias têxteis, indicando a adoção de medidas, como o reuso da água; energia solar e o gerador de ozônio, reduz o consumo de água em cerca de $70 \%$, diminuir de 50 a 70\% o uso dos produtos químicos nos processos e também reduzir o tempo de lavagem em até $50 \%$, diminuindo assim o consumo de energia. Deste modo, estas estratégias surgem como alternativas para a produção sustentável da empresa, a economia do meio ambiente vem auxiliar no controle da gestão ambiental, além de propiciar a inserção em um mercado promissor de consumidores conscientes.

Os fatores que contribuem para o elevado consumo de água nas indústrias/lavanderias têxtis estão associados ao crescimento da demanda comercial por jeans, no entanto, a alteração do perfil do consumidor em buscar de produtos que preservem o meio ambiente poderá vir a ser os maiores influenciadores no aumento do volume de água reutilizada pelas empresas de acordo com dados da UNESCO (2017). Pode-se notar com base nos resultados que as empresas de grande porte do polo têxtil pernambucano já estão visualizando esse diferencial de mercado, uma vez que estão reutilizando mais a água em suas etapas de beneficiamento.

Apesar desses números obtidos com os entrevistados das industrias/lavanderias têxteis (Tabela 2), a observação visual realizada ao redor empresas evidenciou certa contradição entre as informações coletadas nas entrevistas e os fatos observados, o que foi percebido é que, se de fato esse sistema estava em operação, 
ele não trouxe nenhuma melhoria na qualidade do líquido despejado nas águas, uma vez que a coloração da água e o cheiro é característico do ambiente das empresas. Alguns administradores das industrias/lavanderias têxteis alegam que a água, mesmo após o tratamento, ainda contém restos de produtos, o que resulta em uma lavagem de jeans malfeita quando reutilizar-se a água, fato que faz com que os mesmos optem por não reutilizar a água.

As indústrias/lavanderias têxtis possuem áreas que são destinadas ao tratamento dos resíduos gerados nas diferentes etapas de beneficiamento do jeans, estas conhecidas como destinadas para armazenamento do efluente que será reutilizado (Figura $2 \mathrm{~A}$ e B).

Buss et al. (2015) relatam que os efluentes de indústrias/lavanderias são geralmente alcalinos, altamente coloridos, contém grandes quantidades de sabões e detergentes sintéticos, óleos e graxas, sujidades e corantes, além disso apresentam uma demanda bioquímica de oxigênio - DBO 2 a 5 vezes maior que a apresentada pelos esgotos domésticos, além de apresentar elevada carga orgânica, uma baixa tensão superficial e uma quantidade significativa de sólidos suspensos.

A

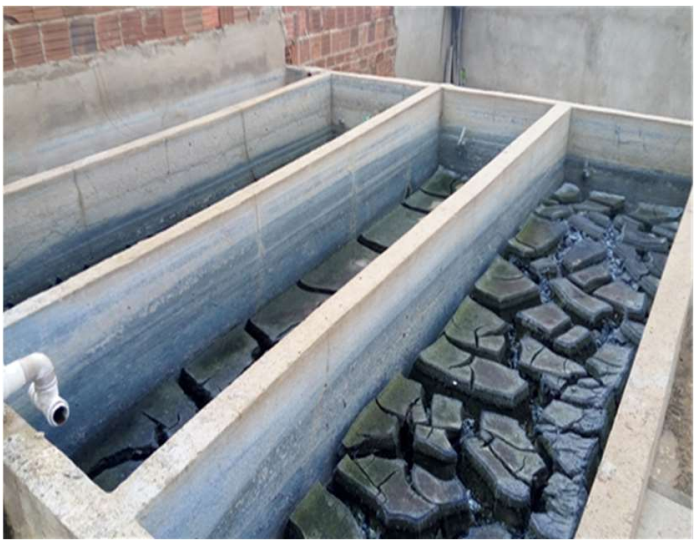

B

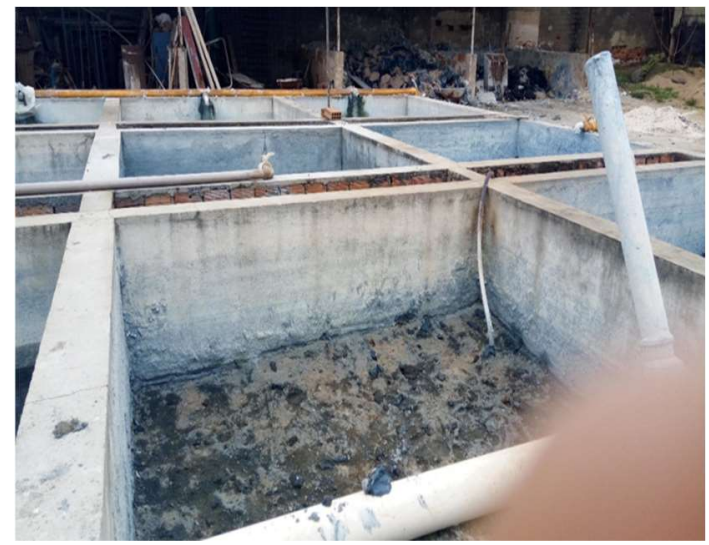

Figura 2: Área destinado ao tratamento da água para reuso das lavanderias de pequeno (A) e médio porte (B).

No processo de beneficiamento de jeans as indústrias/lavanderias têxtis e tinturarias visitadas, constatou-se a concentração dos resíduos químicos, denominado como lodo têxtil. Trata-se de uma substância resultante do tratamento da água utilizada nos diversos processos químicos de lavagem do jeans, apresentando coloração azul dominante (Figuras 2A e B).

No entanto, como é possível observar nas Figuras $2 \mathrm{~A}$ e $\mathrm{B}$, esse processo de tratamento geram quantidades consideráveis de lodo, estes por sua vez possuem em sua constituição a presença de elementos químicos que são tóxicos e extremamente perigosos, pois se constituem em materiais ambientalmente persistentes (ZANELLA et al., 2010).

De acordo com Polli (2013) esse lodo gerado precisa ser destinado corretamente para que não venha a ser um causador de poluição para o ambiente, visando sua valorização, como matéria prima secundária na produção de um material utilizável, com características que atendam os parâmetros exigidos na Lei e sem prejuízo ao ambiente, uma alternativa para esse lodo gerado é a possibilidade de incorporação de até $15 \%$ do lodo na fabricação dos blocos cerâmicos, sem a perda de suas qualidades essenciais.

Zanella et al. (2010) afirma que os efluentes apresentam elevada carga orgânica, alta concentração 
de sais e em muitos casos metais pesados, e forte coloração associada à presença de corantes residuais. Em geral, estima-se que 15 a 50\% da carga de corantes presentes nos efluentes, são oriundas das etapas de descoloração com uso de permanganato de potássio, tingimento e lavagem, sendo que uma parcela importante se mostra recalcitrante, ou seja, resistentes, frente a processos biológicos convencionais, mesmo utilizando-se rotinas anaeróbias-aeróbias sequenciais.

Para Silva et al. (2012) os resíduos sólidos gerados pelas indústrias/lavanderias têxteis são restos de tecidos, embalagens contaminadas com produtos químicos e o "lodo" resultante do tratamento da água, os quais deveriam ser levados para o aterro sanitário, para garantir a não contaminação. No entanto, pelo que se pode observar nas visitas as indústrias/lavanderias têxteis é que algumas relataram enviar o logo para Recife e outras jogam em terrenos baldios ou lixões a céu aberto, ou mesmo no leito dos rios. O processo de lavagem dos jeans tem como grande característica o uso de grande volume de água, após as peças ficarem prontas a lavagem é realizada e serve para amaciar e dar tonalidades diferentes ao tecido. A lavagem consiste basicamente em jogar a peça em uma máquina de lavar junto com objetos (pedras) ou produtos químicos que promovam o amaciamento da peça, bem como um leve desbotamento (Figura 3).

A

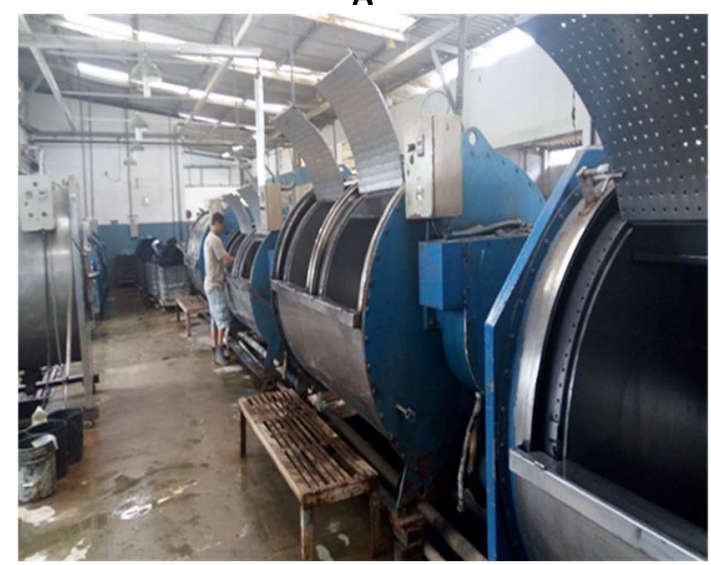

Figura 3: Maquinam utilizadas para fazer a lavagem (A) e centrifugação (B) dos jeans nas industriais/lavanderias

têxteis.
B

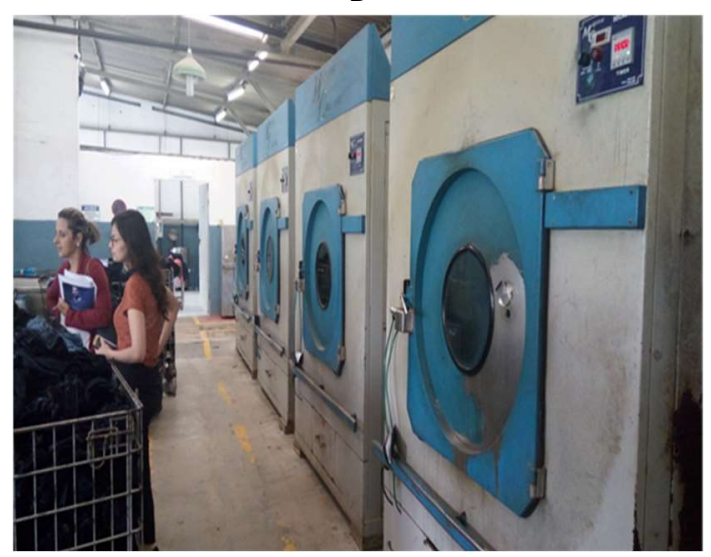

Posteriormente a etapa de lavagem das peças, as mesmas são encaminhadas para a centrifugação e secam em máquinas (Figura 3B) ou dependendo do porte da empresa a secagem das peças também pode ser realizada através da energia solar.

Monteiro et al. (2019) ao estudar aspectos econômico das indústrias de confecções de Toritama - PE afirmam que algumas empresas operam com máquinas próprias durante uma ou duas semanas do mês e no restante contratam serviços de empresas informais familiares espalhados pela cidade e pela área rural.

Com esta prática de terceirização as atividades produtivas são repassadas para empresas informais de lavagem. As indústrias/lavanderias têxteis pagam pelos serviços, e reduzem assim outros custos de produção, como: energia elétrica, manutenção das máquinas, linha para costura, erros na produção, destinação dos resíduos gerados e direitos trabalhistas.

Brandão (2017) relata que a terceirização tem sido praticada em Toritama - PE como uma forma de 
camuflar processos industriais, consome e polui o meio ambiente, em atividades meios que teoricamente, só requerem força de trabalho para a sua execução. A atividade fim de uma empresa não deve ser terceirizada.

\section{Principais produtos químicos utilizados no beneficiamento do jeans}

Os principais produtos químicos utilizados nas indústrias/lavanderias de jeans são: cloro (CC), permanganato de potássio (CPP), metabissulfito de sódio (CMS), amaciante (CA) e metassilicato (CM) em (kg mês ${ }^{-1}$ ) de acordo com o porte das empresas, Tabela 3. Nota-se que o consumo de produtos químicos em kg mês ${ }^{-1}$ aumenta gradativamente de indústrias/lavanderias têxteis de pequeno a médio e grande porte. Dentre os produtos de mais consumo destaca-se o Amaciante que tem como componente principal o peroxido de hidrogênio $\left(\mathrm{H}_{2} \mathrm{O}_{2}\right)$ na fase de amaciamento do jeans, seguido do consumo de cloro na fase de tingimento (Tabela 3).

Tabela 3: Consumo cloro (CC), de permanganato de potássio (CPP), de metabissulfito de sódio (CMS), de amaciante (CA) e de metassilicato (CM) em (kg mês-1) para as lavanderias analisadas de acordo com o porte.

\begin{tabular}{|c|c|c|c|c|c|c|}
\hline \multirow{2}{*}{ Porte das Lavanderias } & \multirow{2}{*}{ Lavanderias } & \multirow{2}{*}{$\frac{\mathrm{CC}\left(\mathrm{kg} \mathrm{mês}^{-1}\right)}{\text { Tingimento }}$} & \multirow{2}{*}{$\begin{array}{l}\text { CPP (kg mês }{ }^{-1} \text { ) } \\
\text { Descoloração }\end{array}$} & \multirow{2}{*}{$\begin{array}{l}\text { CMS (kg mês-1) } \\
\text { Neutralização }\end{array}$} & \multirow{2}{*}{$\begin{array}{l}\text { CA (kg mês }{ }^{-1} \text { ) } \\
\text { Amaciamento }\end{array}$} & \multirow{2}{*}{$\begin{array}{l}\text { CM (kg mês }{ }^{-1} \text { ) } \\
\text { Alvejamento }\end{array}$} \\
\hline & & & & & & \\
\hline \multirow{9}{*}{ Pequeno } & S. C. Capibaribe - A & 60 & 6 & 55 & 130 & 3 \\
\hline & S. C. Capibaribe - B & 65 & 6 & 70 & 135 & 2 \\
\hline & S. C. Capibaribe - C & 55 & 4 & 70 & 120 & 2 \\
\hline & Toritama - A & 120 & 7 & 90 & 250 & 3 \\
\hline & Toritama - B & 90 & 5 & 90 & 150 & 3 \\
\hline & Toritama - C & 120 & 6 & 80 & 150 & 4 \\
\hline & Toritama - D & 100 & 5 & 70 & 130 & 5 \\
\hline & Caruaru - A & 85 & 7 & 90 & 160 & 5 \\
\hline & Caruaru - B & 65 & 5 & 90 & 120 & 5 \\
\hline \multirow{5}{*}{ Médio } & S. C. do Capibaribe - D & 350 & 20 & 300 & 700 & 15 \\
\hline & Toritama - E & 300 & 15 & 250 & 420 & 10 \\
\hline & Caruaru - C & 320 & 17 & 310 & 550 & 11 \\
\hline & Caruaru - D & 500 & 30 & 520 & 1150 & 20 \\
\hline & Caruaru - E & 600 & 35 & 650 & 1200 & 23 \\
\hline \multirow{3}{*}{ Grande } & Toritama - F & 900 & 45 & 850 & 1400 & 35 \\
\hline & Toritama - G & 1000 & 50 & 1000 & 2000 & 40 \\
\hline & Caruaru - F & 800 & 45 & 710 & 1600 & 32 \\
\hline
\end{tabular}

O principal produto químico utilizado no processo de neutralizar o jeans é o metabissulfito sódio para fazer o polimento da peça juntamente com o permanganato de potássio, possuindo relação de banho: RB: 1/4. Para a neutralização, utiliza-se geralmente o metabissulfito sódio e seis litros de água (Tabela 3). Já na etapa de alvejamento, o metassilicato de sódio é o principal produto químico utilizado, usando em média $12 \mathrm{~g} \mathrm{~L}^{-1}$ e para este processo se utiliza 4 litros de água. No amaciamento etapa que se utiliza de peroxido de hidrogênio $\left(\mathrm{H}_{2} \mathrm{O}_{2}\right)$, etapa final do processo de lavagem, usa-se $18 \mathrm{~g} \mathrm{~L}^{-1}$ de amaciante e 3 litros de água (Tabela 3). O elevado consumo de cloro na fase de tingimento ocorre já que após tingir a peça com o corante desejado é necessário realizar o enxague da peça, seguido da oxidação realizada com uma solução de hipoclorito de sódio (Tabela 3). Dentre as etapas de beneficiamento esta é a operação mais complexa, pois abrange um grande número de corantes e auxiliares de tingimento.

O metassilicato de sódio e o permanganato de potássio são os dois produtos químicos menos utilizados nas etapas de beneficiamento de jeans (Tabela 3). O permanganato de potássio é utilizado na 
etapa de descoloração do jeans/Used, ou seja, na etapa que remove a coloração da peça.

As indústrias/lavanderias têxteis iniciam o processo de envelhecimento e desbotamento, com a aplicação do permanganato de potássio que é um agente oxidante e ao entrar em contato com a peça acaba corroendo a cor do índigo causando um efeito esbranquiçado (LOPES, 2011).

De acordo com a Eletrochemical (2017), o permanganato de potássio é uma substância oxidante, que pode causar incêndios quando em contato com outros materiais, além disso, pode causar sérios problemas a saúde dos funcionários das indústrias/lavanderias têxteis. Cabe salientar ainda que, quando dissolvido em solução aquosa pode ser altamente poluente para a vida aquática. O permanganato de potássio também contém em sua composição o metal manganês que pode causar psicose, perda da expressão facial, ausência do ato de piscar, gagueira e insônia, tremores nas mãos, rigidez dos membros e outros sintomas similares à doença de Parkinson, além disso pode permanecer nos corpos hídricos por longos períodos de tempo.

Lopes (2011), afirma que outro produto já está disponível no mercado visando a substituição do permanganato de potássio é o chamado used ecológico, porém as lavanderias ainda não conseguiram fazer a substituição do produto por completo.

A utilização de produtos ecológicos por indústrias/lavanderias têxteis possibilita a inutilização do hipoclorito de sódio, que juntamente com o permanganato de potássio são grandes agentes poluidores, além de causarem danos à saúde dos colaboradores. Nesse sentido, a utilização de produtos socioambientalmente corretos podem trazer inúmeros benefícios para o meio ambiente e também podem diminuir o consumo de energia e água pelas empresas (SILVA et al., 2012; LOPES, 2011; POLLI, 2013).

Estas e outras medidas corretivas foram discutidas no Congresso da Associação Brasileira de Técnicos Têxteis em 2011, onde grandes marcas de jeans apresentaram suas tecnologias sustentáveis, como a utilização da marcação no jeans por laser que substituir o jato de areia, o permanganato de potássio e o esmeril; outra técnica é o uso do ozônio, que reduz o uso da água e a utilização de produtos químicos (SINDILAV, 2017).

\section{CONCLUSÕES}

O consumo de água bruto, de produto químico, o reuso e a produção de jeans eleva-se, à medida que as empresas crescem com relação ao porte. O produto comercial denominado Amaciante, princípio ativo peroxido de hidrogênio é o mais utilizado pelas indústrias/lavanderias têxteis no agreste pernambucano.

Quanto maior o porte da indústria/lavanderia têxtil mais elevado o consumo de água, produtos químicos e efluentes lançados nos rios. O permanganato de potássio é um dos produtos químicos utilizados no beneficiamento de jeans, mais poluentes e persistentes em meios aquáticos.

As indústrias/lavanderias têxteis são grandes agentes poluidoras, uma vez que usam elevados volumes de água e produtos químicos, necessitando de normas mais rígidas quanto a emissão e despejos de seus resíduos. Faz-se necessário a busca por alternativas visando reduzir o consumo de água bruta, como reuso, manutenção continua de maquinas e substituição de produtos químicos poluentes por técnicas sustentáveis. 


\section{REFERÊNCIAS}

ALKAYA, E.; DEMIRER, G. N.. Sustainable textile production: a case study from a woven fabric manufacturing mill in Turkey. Journal of Cleaner Production, v.65, n.1, p.595-603. 2014. DOI: http://dx.doi.org/10.1016/j.jclepro.2013.07.008

ALMEIDA, A. M. B.. Roupa suja se lava em casa: A seca no agreste pernambucano e a gestão ambiental na lavanderia Água Limpa. Revista Administração Pública e Gestão Social, v.5, n.2, p.134-138, 2013.

ARAÚJO, W. C.; JESUS, J. O. N.; PEDRO, F. J. D.; RODRIGUES, L. K. O.; SANTOS, D. S.; SANTOS, I. S.. Estudo socioeconômico do Polo de Confecções no Agreste de Pernambuco: uma análise descritiva e exploratória. Brazilian Journal of Development, v.5, n.11, p.26812-26826, 2019. DOI: https://doi.org/10.34117/bjdv5n11-304

BARROS, R. M.. Tratado sobre resíduos sólidos: gestão, uso e sustentabilidade. Rio de Janeiro: Interciência, 2012.

BELTRÃO, B. A.; MASCARENHAS, J. C.; MIRANDA, J. L. F.; SOUZA JUNIOR, L. C.; GALVÃO, M. J. T. G.; PEREIRA, S. N.. Diagnóstico do Municí pio dos municípios do agreste de Pernambuco. Projeto cadastro de fontes de abastecimento por água subterrânea. CPRM - Serviço Geológico do Brasil, 2005.

BRANDÃO, A. L.. Instrumentos de Política Ambiental em Pernambuco: O Caso das Lavanderias de Toritama. Revista Científica Multidisciplinar Núcleo do Conhecimento, v.01. n.2, p.421-445, 2017.

BUSS, M. V.; RIBEIRO, E. F.; SCHNEIDER, I. H.; MENEZES, J. C. S. S.. Tratamento dos efluentes de uma lavanderia industrial: avaliação da capacidade de diferentes processos de. 85 tratamentos. Revista de Engenharia Civil IMED, v.2, n.1, p.210, 2015. DOI: https://doi.org/10.18256/2358-6508/recimed.v2n1p2-10

COSTA, G. C. B.; FERREIRA, M. O.. Indicação de alocação dos custos em projetos de despoluição: uma análise das bacias hidrográficas dos Rios Ipojuca e Capibaribe. Revista Estudo \& Debate, v.26, n.3, p.124-151, 2019. DOI:

http://dx.doi.org/10.22410/issn.1983-

036X.v26i3a2019.2105

DONAIRE, D.. Gestão Ambiental na empresa. 2 ed. São Paulo: Atlas, 2011.

ELETROCHEMICAL. Ficha de informações de segurança de produto químico: FISPQ/Permanganato de potássio. Limeira, 2017.

JERÔNIMO, T. B.; GALVÃO M. B.; FALCÃO, J. M. S. L.. Proposta de utilização do environment to businesses em projetos de recursos hídricos de despejo de produtos químicos: estudo de caso das lavanderias no município de Toritama. Revista Eletrônica Serviços e Gestão, v.7, n.3, p.366-378. 2012. DOI:

http://dx.doi.org/10.7177/sg.2012.v7.n3.a6

LOPES, C. S. D.. Análise ambiental da fase de acabamento do jeans. Revista de Saúde, Meio Ambiente e Sustentabilidade, v.6, n.3, p.87-102, 2011.
LORENA, E. M. G.; SANTOS, I. G. S.; GABRIEL, F. A.; BEZERRA, A. P. X. G.; RODRIGUEZ, M. A. M.; MORAES, A. S.. Analysis of the procedural and wastewater treatment at a beverage bottling industry in the state of Pernambuco, Brazil. Revista Geama, v.2, n.4, p.466-472, 2016.

MARCELINO, D. M. S.. Avaliação da remoção de cor, matéria orgânica e sulfato de efluente têxtil através de reatores biológicos sequenciais. Dissertação (Mestrado em Engenharia Civil e Ambiental) - Universidade Federal de Pernambuco, Caruaru, 2013.

MONTEIRO, A.; QUESADA, E.; VIEIRA, R.. Estudo Econômico das Indústrias de 1 Confecções de Toritama/PE. SEBRAE, 2019.

POLLI, A.. Gerenciamento de impactos ambientais em lavanderias têxteis. Revista Brasileira de Gestão Ambiental, v.7, n.2, p.12-18, 2013.

PINILLA, C. M. B.; NOREÑA, C. P. Z.; BRANDELLI, A.. Development and characterization of phosphatidylcholine nanovesicles containing garlic extract with antilisterial activity in milk. Food Chemistry, v.220, p.470-476, 2017. DOI:

http://dx.doi.org/10.1016/i.foodchem.2016.10.027.PMid:27 855927

SEBRAE. Serviço Brasileiro de Apoio às Micro e Pequenas Empresas. Eficiência da Economia e Competitividade da Cadeia Têxtil Brasileira. SEBRAE, 2017.

SEBRAE. Serviço de Apoio As Micro e Pequenas Empresas. Lavanderias do Agreste ganham Selo Verde. SEBRAE, 2013.

SILVA, B. L.; XAVIER, M. G. P.. Inovação e tecnologia em lavanderias de jeans do polo têxtil do agreste Pernambucano e a implementação das atividades de reuso de água. Braz. J. of Develop., v.6, n.6, p.41458-41476. 2020. DOI: http://dx.doi.org/110.34117/bjdv6n6-620

SILVA, M. V. A.; SILVA, A. L.; BRITO, D. J. M.; BRANCO, D. K. S.; FERREIRA, M. O.. A questão ambiental no pólo de confecções de Caruaru: um primeiro ensaio à luz dos instrumentos econômicos de proteção ambiental. Revista Estudos do CEPE, n.35, v.8, p.108-132, 2012. DOI: http://dx.doi.org/10.17058/cepe.v0i35.2389

SINDILAV. Sindicato das Lavanderias e Similares do Rio Grande do Sul. Cartilha de boas práticas ambientais para lavanderia. SINDILAV, 2017.

SINDITÊXTIL. Sindicato das Indústrias Têxteis do Estado de São Paulo. Têxtil e confecção: inovar, desenvolver e sustentar. Brasília: CNI/ABIT, 2017.

UNESCO. United Nations Educational Scientific and Cultural Organization. Relatório mundial das nações unidas sobre o desenvolvimento dos recursos hídricos. Fatos e Números. UNESCO, 2017.

VIANA, M. A.; LIRA, E. B. S.; COELHO, C. P. G.; BEZERRA, A. P. X. G.; LORENA, E. M. G.; HOLANDA, R. M.. Pegada hídrica em indústria de beneficiamento de jeans no Agreste Pernambucano. Journal of Environmental Analysis and 
Progress., v.03, n.01, p.061-068, 2018. DOI:

https://doi.org/10.24221/jeap.3.1.2018.1723.061-068

ZANELLA, G.; SCHARF, M.; VIEIRA, G. A.; PERALTA-ZAMORA,
P.. Tratamento de banhos de tingimento têxtil por processos foto-Fenton e avaliação da potencialidade de reúso. Química Nova, v.33, n.5, p.1039-1043, 2010. DOI:

https://doi.org/10.1590/S0100-40422010000500006

A CBPC - Companhia Brasileira de Produção Científica (CNPJ: 11.221.422/0001-03) detém os direitos materiais desta publicação. Os direitos referem-se à publicação do trabalho em qualquer parte do mundo, incluindo os direitos às renovações, expansões e disseminações da contribuição, bem como outros direitos subsidiários. Todos os trabalhos publicados eletronicamente poderão posteriormente ser publicados em coletâneas impressas sob coordenação da Sustenere Publishing, da Companhia Brasileira de Produção Científica e seus parceiros autorizados. Os (as) autores (as) preservam os direitos autorais, mas não têm permissão para a publicação da contribuição em outro meio, impresso ou digital, em português ou em tradução. 